\title{
A quick and easy high performance liquid chromatography method for evaluation of cefixime in human plasma
}

\author{
Hossein Danafar* \\ ${ }^{1}$ Zanjan Pharmaceutical Nanotechnology Research Center, Zanjan University of Medical Sciences, Zanjan, Iran \\ ${ }^{2}$ Department of Medicinal Chemistry, School of Pharmacy, Zanjan University of Medical Sciences, Zanjan, Iran

\begin{abstract}
Cefixime is essential member of orally energetic third generation cephalosporin and has tremendous activity aligned with many pathogens. The virtual bioavailability of a newly industrial dispersible tablet as compared with a recognized identified formulation. A simple and available reversed-phase HPLC method with UV detection has been urbanized and validate for cefixime evaluate in human plasma using a C18 analytical column and a mobile phase of tetrabutylammonium hydroxide $(\mathrm{pH} 6.5)$-acetonitrile (3:1 $\mathrm{v} / \mathrm{v})$. The detection wavelength was $280 \mathrm{~nm}$. To method observed major linear response-concentration association all through the cefixime concentration range of 15$100 \mathrm{ng} / \mathrm{ml}$, with the average accuracy within-run and between-run values of $97.29 \%$ and 99.27\%. The average drug recovery from plasma was $98.2 \%$ throughout the linear concentration range. The limits of detection (LOD) and quantitation (LOQ) of the method were 5 and $15 \mathrm{ng} / \mathrm{ml}$, respectively. The method is quick, easy, very steady and precise for the partition, assignment, evaluation of cefixime in human plasma.
\end{abstract}

Keywords: Cefixime, human plasma, reversed-phase HPLC

Pharm Biomed Res 2015; 1(4): 29-39～DOI: 10.18869/acadpub.pbr.1.4.29

\section{Introduction}

Cefixime (Fig. 1) [(6R, 7R, E)-7-(2-(2amino thiazol-4-yl)-2- carboxy methoxy imino) acetamido)-8-oxo-3-vinyl-5thia-1-azabicyclo [4.2.0] oct-2-ene-2carboxylic acid] is belong to third generation of cephalsporin. The cefixime exists in off white crystals, melts over $220-250{ }^{\circ} \mathrm{C}$ and soluble in alcohol (1). An orally active cefixime has outstanding activity against pathogens such as, Anaerobes, Entero bacteria ceae, gram negative species such as Escherichia coli, Klebsiella, Haemophilus influenzae, Branhamella Catarrhalis, Neisseria gonorrhoeae, Serratiamarcescens, Providencia,
Haemophilus, and Meningococcus including $b$-lactamase producing strains (1-3). Along with its broad spectrum antimicrobial activity and stability, cefixime was used as most suitable in proper dosage for adults as well as pediatrics and widely arranged among cephalosporin family in Iran. in spite of its poor lipophilicity and ionization at physiological $\mathrm{pH}$, cefixime is significantly absorbed unaffected after oral administration (4). The absolute oral bioavailability of cefixime is in the range of 22-54\%. Absorption is not appreciably customized by the presence of food. Cefixime may therefore be 
<smiles>C=CC1=C(C(=O)O)N2C(=O)[C@@H](NC(=O)/C(=N/OCC(=O)O)c3csc(N)n3)[C@H]2SC1</smiles>

Figure 1 Chemical structure of cefixime

offered without observe to meals. Following oral dosing, cefixime attain peak serum levels in approximately $4 \mathrm{~h}$ (5). From in vitro studies, serum or urine concentrations of $1 \mu \mathrm{g} / \mathrm{ml}$ or greater were measured to be adequate for most general pathogens beside which cefixime is active. The half-life is about 3 to $4 \mathrm{~h}$ and is not dose needy. Cefixime is excreted by renal and biliary mechanisms. About $50 \%$ of the absorbed dose is excreted unchanged in the urine within $24 \mathrm{~h}$. There is no verification of metabolism of cefixime in vivo. Serum protein binding is well characterized for human and animal sera; cefixime is almost completely bound to the albumin fraction, the mean free fraction being approximately $30 \%$. Protein binding of cefixime is concentration dependent in human serum only at very high concentrations which are not seen following clinical dosing (4). The area under the time versus concentration curve is superior by about $26.4 \%$ and the Cmax is bigger by around $20.7 \%$ with the oral suspension when compared to the tablet after doses of $400 \mathrm{mg}$. This enlarged absorption should be taken into consideration, if the oral suspension is to substitute the tablet. There are several investigations relating to the evaluation of cefixime alone and in combination with other drugs in pharmaceutical planning and plasma by UV, HPLC, LC-MS, HPTLC methods (6-13). These methods engage spectrophotometric methods (14-15), voltammetric method (16), capillary electrophoresis (17). Though, HPLC is much more complicated technique as compared to in the past reported methods as it provides gangrenous information for all analytes along with consequent UV/ Vis spectra concurrently, which is very useful tool for the analysis of unknown mechanism of a mixture. The pervious our works was determination of drugs by LC-MS method in human plasma (18-22). In this way, a simple HPLC-UV method is residential and validated for cefixime analyze in human plasma.

\section{Matterials and methods}

\section{Materials}

Cefixime test tablets (Exir), Cefixime reference tablets (Wyeth) and cefixime reference standard (99.9\% purity) were abounding and branded by Wyeth. Other chemicals and solvents were from chemical lab or HPLC purity grades, whenever needed, and were purchased. Drug-free human plasma was provided by Iranian Blood Transfusion Organization after routine safety evaluations.

\section{Instrument and HPLC method}

The HPLC system consisted of a double-reciprocating pump (Waters, model 600, MA, USA), a variable wavelength UV detector (Waters, model 2478, MA, USA) used at a wavelength of $280 \mathrm{~nm}$ with the outputs recorded and analysed using a compatible software (Millennium $^{\circledR}$, Waters, MA, USA). The drug separation was performed using a $\mathrm{C}_{18}$ analytical column 
$(250 \mathrm{~mm} \times 4.6 \mathrm{~mm}$, particle size $5 \mu \mathrm{m}$; Perfectsill, MZ-Analysentechnik, Germany) arranged by a guard column of the same packing. The mobile phase was composed of tetrabutylammonium hydroxide $(\mathrm{pH}$ 6.5)-acetonitrile (3:1) with a flow rate of $1 \mathrm{ml} / \mathrm{min}$. Sample injection to system $(50 \mu \mathrm{L})$ was made by a loop injector (Rheodyne ${ }^{\circledR} 7725 \mathrm{i}$, Cotati, CA, USA).

\section{Standard preparation}

A stock solution of $1000 \mathrm{ng} / \mathrm{ml}$ cefixime in phosphate buffer ( $\mathrm{pH}$ 7.4) was geared up, from which the concentrations of $15,25,50,75$ and $100 \mathrm{ng} / \mathrm{ml}$ were prepared by serially diluting this solution with the proper amount of phosphate buffer ( $\mathrm{pH} 7.4)$. A series of spiked plasma samples with cefixime concentrations of $15,25,50,75$ and 100 $\mathrm{ng} / \mathrm{ml}$ were prepared by $1: 10$ dilution of the described solutions with drug-free human plasma.

\section{Assay procedure}

To $150 \mu \mathrm{L}$ calibration standards, QC samples, or plasma samples, $12 \mu \mathrm{L}$ perchloric acid $\left(\mathrm{HClO}_{4} \quad 75 \%\right.$ aqueous solution) and $400 \mu \mathrm{L}$ methanol and 100 $\mu \mathrm{L}$ acetonitrile were added. The mixtures were vortex mixed for $20 \mathrm{~s}$. After centrifugation at $15000 \times \mathrm{g}$ in an eppendorf micro centrifuge tubes for 20 min, $50 \mu \mathrm{L}$ of the supernatant was injected directly onto the analytical column for immediate HPLC analysis.

\section{System suitability tests}

The following parameters were calculated as system suitability indices of the developed method:

Number of theoretical plates $(\mathrm{N})=16$ $\left(t_{R} / w\right)^{2}$

Peak symmetry $=\mathrm{w} / 2 \mathrm{f}$

Retain ability $\left(\mathrm{K}^{\prime}\right)=\left(\mathrm{t}_{\mathrm{R}} / \mathrm{t}_{\mathrm{a}}\right)-1$
Where, $t_{R}$ is the retention time of the analyte, $\mathrm{w}$ is the width of the analyte peak at its 0.05 height, $\mathrm{f}$ is the front half-width of the analyte peak at its 0.05 height and $t_{a}$ is the retention time of non-retained analyte (solvent front).

\section{Analysis validation tests}

\section{Standard curve (linear range)}

The plasma samples with a series of known concentrations, prepared as described, were analyzed in three separate runs and, in each case, the linear regression analysis was carried out on known concentrations of cefixime against the corresponding peak heights and, then, the regression coefficient (r), slope, and y-intercept of the resulting calibration curves were determined.

\section{Within-run variations}

In one run, three samples with concentrations of 15,50 , and $100 \mathrm{ng} / \mathrm{ml}$ (from low, middle, and high regions of the standard curve) were prepared in triplicate and analyzed by developed HPLC method. Then, the coefficient of variations $\%(\mathrm{CV})$ of the corresponding determined concentrations were calculated in each case.

\section{Between-run variations}

On three different runs, samples from upper, intermediate, and lower concentration regions used for construction of standard curve (the same as within-run variations test) were prepared and analyzed by HPLC method. Then, the corresponding \% CV values were calculated.

\section{Absolute recovery (accuracy)}

For each sample tested for within- and between-run variations, the absolute recovery of the method was determined 
as the percent ratio of the measured concentration (determined using standard curve) to the corresponding nominal added concentration.

\section{Relative recovery (matrix effect)}

Three samples with concentrations of 15, 50, and $100 \mathrm{ng} / \mathrm{ml}$ (from high, middle, and low regions of the standard curve) were prepared in triplicate and analyzed by developed HPLC method. Then, the ratio of the recorded peak heights to the peak heights resulted from the direct injection of the aqueous solutions of cefixime with the same concentrations were determined as percentage in each case.

\section{Limits of detection and quantitation}

Limit of detection (LOD) of the method was determined as the lowest cefixime concentration producing a signal-tonoise $(\mathrm{S} / \mathrm{N})$ ratio of about 3 . Limit of quantitation (LOQ) was determined as the lowest cefixime concentration capable of being quantities with enough accuracy and precision.

\section{Repeatability test}

For determination repeatability of method, concentration of $50 \mathrm{ng} / \mathrm{ml}$ of six independent spiked plasma samples were prepared as described. For the repeatability of the method a single injection of each preparation was made to HPLC and the \%RSD between the results was determined.

\section{Intermediate precision}

The study of repeatability on a different day, a second analyst executed analysis of a further six samples prepared as described in repeatability test procedure. The analysis was performed by using fresh reagents and a different HPLC column. The \%RSD between six measurements was determined along with the \%RSD between the total of 12 measurements from the repeatability and intermediate precision tests.

\section{Reproducibility}

For assay of reproducibility mean results for the same sample analysis between our laboratory and two different test facilities were obtained and the percentage of difference between content measurements was calculated using the equation:

[(highest value - lowest value) /mean value] $\times 100$.

\section{Stability:}

\section{Freeze and thaw stability}

For determination of stability in freezer storing the three concentration levels of QC plasma samples temperature $\left(-20{ }^{\circ} \mathrm{C}\right)$ for $24 \mathrm{~h}$ and thawed unassisted at room temperature. After complication of thawed, the samples were refrozen for $24 \mathrm{~h}$ under the same conditions. Twice repeated the freeze-thaw cycle, then the samples were tested after three freeze $\left(-20{ }^{\circ} \mathrm{C}\right.$ )-thaw (room temperature) cycles.

\section{Short-term temperature stability}

For determination of stability to kept at room temperature three concentration levels of QC plasma samples for a period that exceeded the routine preparation time of samples (around 6 h).

\section{Long-term stability}

For determination of stability the QC plasma samples of three concentration 
levels at low temperature $\left(-20^{\circ} \mathrm{C}\right)$ were studied for a period of 4 weeks.

Standard curve and quality control sample in each batch

To calculate the concentration of cefixime in the unknown samples in the run was using of the standard curve in each analytical run. It was prepared at the same time as the unknown samples in the same batch and analyzed in the middle of the run. For analyzing of the QC samples in five duplicates at three concentrations (15, 50.0 and 100.0 $\mathrm{ng} / \mathrm{ml}$ ) were prepared with processed test samples at intervals per batch.

\section{Results}

\section{Method development}

In response to lack of an accessible, consistent, and simple to use analysis method for cefixime assay in plasma as an vital part of pharmacokinetic and bioequivalence estimate projects on the drug we urbanized a simple and offered HPLC method with UV detection based on the available equipments found in most pharmaceutical laboratories. To this end, initially a series of isocratic as well as gradient conditions using different usual mobile phase compositions, polarities, ionic strengths, and $\mathrm{pH}$ values were tested in order to determine the best condition for the analyte separation.

\section{System suitability tests}

The number of theoretical plates $(\mathrm{N})$, peak symmetry, and retain ability $\left(\mathrm{K}^{\prime}\right)$ of the method for cefixime were 1296, 1.143 , and 2.75 , respectively. These data show that the developed method is of appropriate separation efficiency and peak shape, both of which are important factors in estimate of the chromatographic method outputs.

Typical chromatograms produced from the developed method are shown in figure 2. Figure 2.A shows the spiked plasma sample with cefixime concentration of $100 \mathrm{ng} \mathrm{mL}^{-1}$, the retention times of cefixime was 6.67 min and the total HPLC analysis time was $7 \mathrm{~min}$ per sample. Figure 2.B shows a representative chromatogram of a plasma sample obtained at $7 \mathrm{~h}$ from a subject who received a single oral dose $(400 \mathrm{mg})$, no interferences of the analyte were observed of the method(Fig. 2.C LOD, Fig. 2.D LOQ). The HPLC chromatogram for a blank plasma sample indicating no endogenous peaks at the retention positions of cefixime was shown in Figure 2.E.

\section{Method validation tests: \\ Linearity}

The method produced linear responses throughout the cefixime concentration range of $15-100 \mathrm{ng} / \mathrm{ml}$, which is suitable for intended purposes. A typical linear regression equation of the method was: $\mathrm{y}=8.5564 \mathrm{x}+0.0654$, with $\mathrm{x}$ and $\mathrm{y}$ representing cefixime concentration (in $\mathrm{mcg} / \mathrm{ml}$ ) and peak height (in arbitrary units), respectively, and the regression coefficient $\left(\mathrm{r}^{2}\right)$ of 0.9916 .

\section{Within-run variations and accuracy}

The within-run variations of the developed HPLC method as well as the corresponding absolute recoveries are shown in table1.

Between-run variations and accuracy The between-run variations of the developed HPLC method as well as the corresponding absolute recoveries are shown in table 2. 


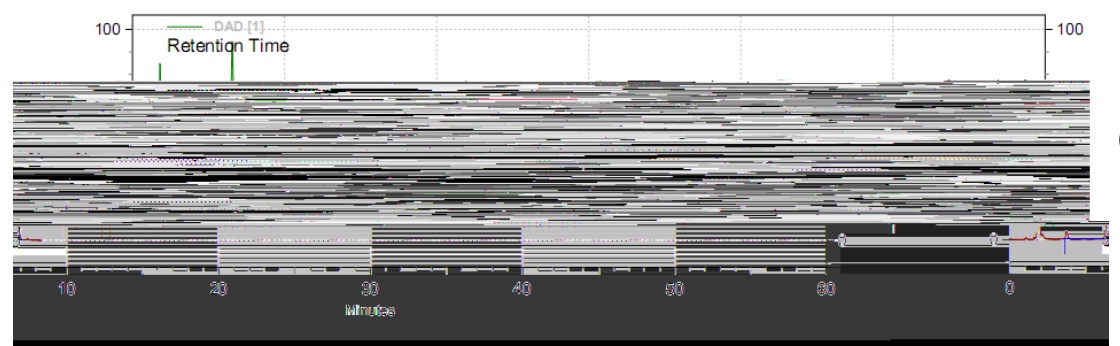

(A)

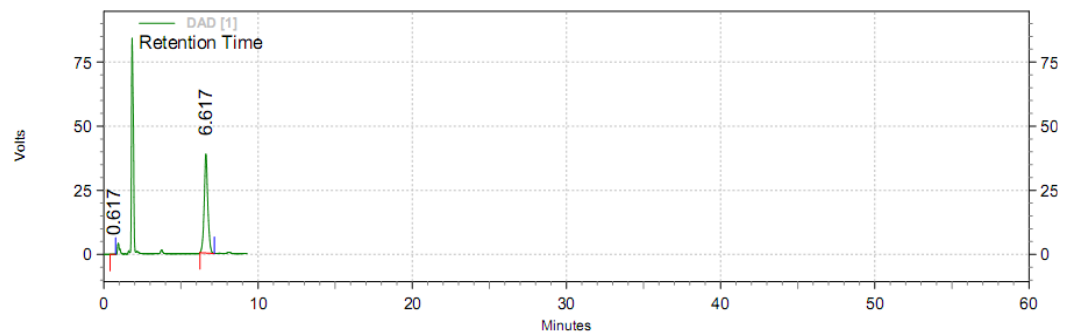

(A)

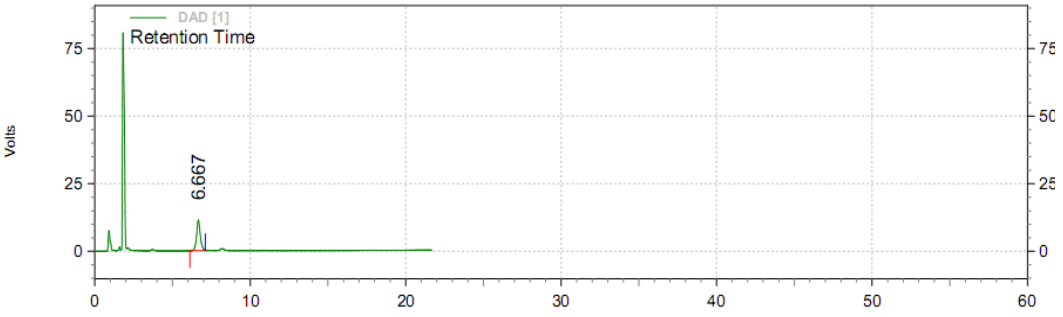

(C)

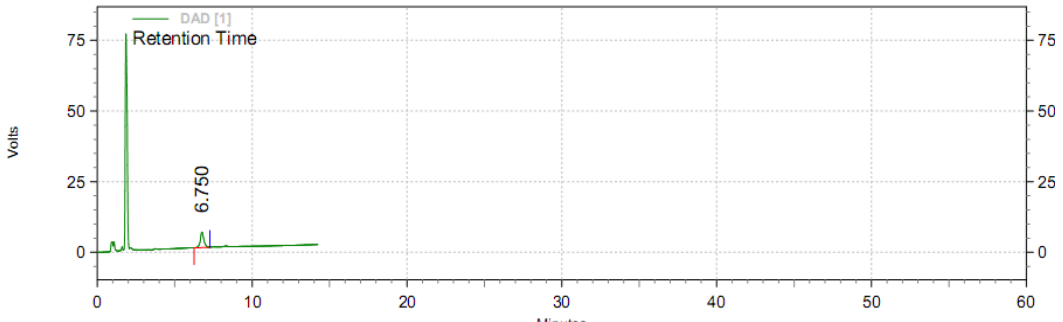

(D)

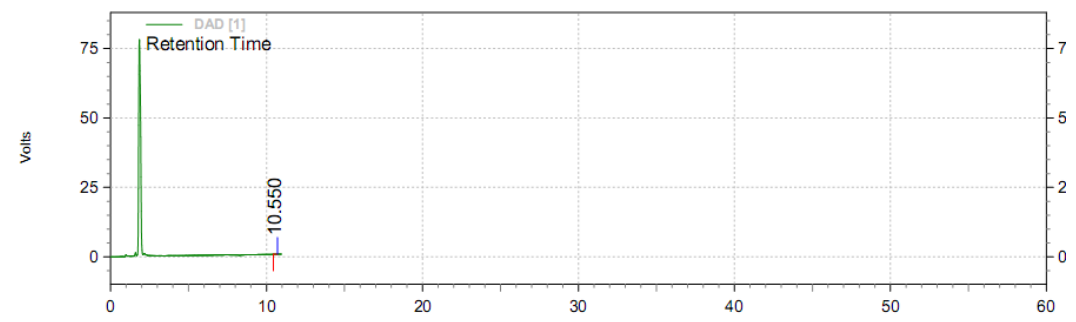

(E)

Figure 2 Typical chromatograms of the HPLC method developed for cefixime assay in human plasma: Fig. 2 A) human plasma spiked to a $100 \mathrm{ng} / \mathrm{ml}$ drug concentration; Fig. 2.B chromatogram of a plasma sample obtained at $7 \mathrm{~h}$ from a subject who received a single oral dose $(400 \mathrm{mg})$; Fig. 2.C LOD, Fig. 2.D LOQ of the method; Fig. 2.E the HPLC chromatogram for a blank plasma. 
Table 1Within-run variations and accuracy of the HPLC method for quantitation of cefixime $(n=3)$.

\begin{tabular}{ccccccc}
\hline $\begin{array}{c}\text { Nominal added } \\
\text { concentration } \\
(\mathrm{ng} / \mathrm{ml})\end{array}$ & $\begin{array}{c}\text { Sample } \\
\text { number }\end{array}$ & $\begin{array}{c}\text { Measured } \\
\text { concentration } \\
(\mathrm{ng} / \mathrm{ml})\end{array}$ & $\begin{array}{c}\text { Mean } \pm \\
\text { SD }\end{array}$ & CV\% & Accuracy & $\begin{array}{c}\text { Mean } \pm \\
\text { SD }\end{array}$ \\
\hline 15 & 1 & 15.22 & $15.01 \pm$ & 1.22 & 95.23 & $95.54 \pm$ \\
& 2 & 14.95 & 0.18 & & 94.36 & 1.37 \\
\hline 50 & 3 & 14.87 & & & 97.05 & \\
\hline & 1 & 49.51 & $50.22 \pm$ & 3.39 & 99.24 & $97.12 \pm$ \\
& 2 & 52.17 & 1.7 & & 95.89 & 1.84 \\
\hline 100 & 1 & 48.99 & & & 96.23 & \\
\hline & 2 & 101.32 & 0.93 & & 99.02 & 0.70 \\
& 3 & 100.23 & & & 98.65 & \\
\hline
\end{tabular}

Table 2 Between-run variations and accuracy of the HPLC method for quantitation of cefixime $(n=3)$.

\begin{tabular}{ccccccc}
\hline $\begin{array}{c}\text { Nominal added } \\
\text { concentration } \\
(\mathrm{ng} / \mathrm{ml})\end{array}$ & $\begin{array}{c}\text { Run } \\
\text { number }\end{array}$ & $\begin{array}{c}\text { Measured } \\
\text { concentration } \\
(\mathrm{ng} / \mathrm{ml})\end{array}$ & $\begin{array}{c}\text { Mean } \pm \\
\text { SD }\end{array}$ & CV\% & Accuracy & $\begin{array}{c}\text { Mean } \pm \\
\text { SD }\end{array}$ \\
\hline 15 & 1 & 15.01 & $14.78 \pm$ & 2.42 & 97.90 & $99.23 \pm$ \\
& 2 & 14.36 & 0.36 & & 98.78 & 1.62 \\
& 3 & 14.99 & & & 101.02 & \\
\hline 50 & 1 & 50.32 & $49.68 \pm$ & 1.51 & 96.55 & $98.79 \pm$ \\
& 2 & 49.87 & 0.75 & & 101.23 & 2.34 \\
& 3 & 48.85 & & & 98.59 & \\
\hline 100 & 1 & 100.16 & $99.86 \pm$ & 0.3 & 101.02 & $99.63 \pm$ \\
& 2 & 99.87 & 0.3 & & 99.32 & 1.25 \\
& 3 & 99.56 & & & 98.56 & \\
\hline
\end{tabular}




\section{Relative recovery}

The relative recovery of cefixime using the developed assay method is shown in table 3 .

Table 3 Relative recovery of cefixime by the HPLC method $(\mathrm{n}=3)$

\begin{tabular}{cccc}
\hline $\begin{array}{c}\text { Nominal } \\
\text { added } \\
\text { concentration } \\
(\mathrm{ng} / \mathrm{ml})\end{array}$ & $\begin{array}{c}\text { Sample } \\
\text { number }\end{array}$ & $\begin{array}{c}\text { Recovery } \\
(\%)\end{array}$ & $\begin{array}{c}\text { Mean } \pm \\
\text { SD }\end{array}$ \\
\hline 15 & 1 & 95.21 & $98.77 \pm$ \\
& 2 & 102.01 & 3.41 \\
& 3 & 99.11 & \\
\hline 50 & 1 & 96.18 & $96.62 \pm$ \\
& 2 & 101.14 & $4.30)$ \\
& 3 & 92.56 & \\
\hline 100 & 1 & 101.25 & $99.21 \pm$ \\
& 2 & 102.04 & 4.22 \\
& 3 & 94.36 & \\
\hline
\end{tabular}

\section{Limit tests}

The limits of detection (LOD) and quantitation (LOQ) of the method were 5 and $15 \mathrm{ng} / \mathrm{ml}$, respectively.

In general, the results of the validation tests indicated that the developed method has a remarkable degree of accuracy, repeatability, reproducibility, and recovery with application limits being in the desired range for routine applications.

\section{Repeatability test}

A remarkable repeatability for the drug assay in plasma for this development method by results as shown in Table 4 .

\section{Intermediate precision}

As indicated, of the results the developed method shows in Table 5 anacceptable intermediate precision for cefixime assay of the intermediate precision.

\section{Reproducibility}

The highest test result of the spiked plasma with $50 \mathrm{ng} \mathrm{mL}^{-1}$ cefixime was 123654 and the lowest value was 122867 with the mean value of 123188 . Therefore, the percentage of difference was $0.63 \%$ which means a high reproducibility for the method.

\section{Stability}

The results are shown in table 6 summarizes the freeze and thaw stability, short term stability, long-term stability and post-preparative stability data of cefixime. The stability behavior during these tests and there were no stability related problems during the samples routine analysis for the pharmacokinetic, bioavailability or bioequivalence studies. Based on the results obtained, the working solutions were stable within $6 \mathrm{~h}$ by tested stability of working solutions at room temperature.

\section{Discussion}

Cefixime is essential member of orally energetic third generation cephalosporin and has tremendous activity aligned with many pathogens. The virtual bioavailability of a newly industrial dispersible tablet as compared with a recognized identified formulation. There are several investigations relating to the evaluation of cefixime alone and in combination with other drugs in pharmaceutical planning and plasma by UV, HPLC, LC-MS, HPTLC methods (6-13). These methods engage spectrophotometric methods (14-15), voltammetry method (16), capillary electrophoresis (17). Though, HPLC is much more complicated technique as compared to in the past reported methods as it provides gangrenous information for all analytes along with 
Table 4 Repeatability of the test results for spiked plasma containing $50 \mathrm{ng} \mathrm{mL} \mathrm{m}^{-1}$.

\begin{tabular}{ccccccc}
\hline Sample & Peak area & Mean \pm SD & CV\% & $\begin{array}{c}\text { Retention } \\
\text { time (min) }\end{array}$ & Mean \pm SD & CV\% \\
\hline & & & & & & \\
1 & 123546 & $123188.2 \pm 326.98$ & 0.26 & 6.61 & $6.65 \pm 0.05$ & 0.88 \\
2 & 123054 & & & 6.63 & & \\
3 & 122987 & & 6.68 & \\
4 & 123654 & & 6.75 & \\
5 & 122867 & & 6.59 & \\
6 & 123021 & & 6.62 & \\
\hline
\end{tabular}

Table 5 Intermediate precision of the test results for spiked plasma containing $50 \mathrm{ng} \mathrm{mL} \mathrm{m}^{-1}$ cefixime

\begin{tabular}{ccccccc}
\hline Sample & Peak area & Mean \pm SD & CV\% & $\begin{array}{c}\text { Retention } \\
\text { time (min) }\end{array}$ & Mean \pm SD & CV\% \\
\hline 1 & 122956 & $123190.8 \pm 351.77$ & 0.28 & 6.61 & $6.64 \pm 0.07$ & 1.12 \\
2 & 122863 & & & 6.55 & & \\
3 & 123065 & & 6.63 & \\
4 & 123620 & & 6.71 & \\
5 & 122987 & & 6.75 & \\
6 & 123654 & & 6.60 & \\
\hline
\end{tabular}

Table 6 Data showing stability of cefixime in human plasma at different QC levels $(n=5)$

\begin{tabular}{cccc}
\hline Stability & $15(\mathrm{ng} / \mathrm{ml})$ & $50(\mathrm{ng} / \mathrm{ml})$ & $100(\mathrm{ng} / \mathrm{ml})$ \\
Short-term stability & 95.45 & 94.32 & 91.01 \\
\cline { 1 - 1 } Freeze and thaw stability & 97.85 & 96.54 & 98.12 \\
\cline { 1 - 1 } Long-term stability & 96.32 & 98.21 & 96.32 \\
\cline { 1 - 1 } Post-preparative stability & 98.12 & 92.30 & 94.12 \\
\hline
\end{tabular}


consequent UV/ Vis spectra concurrently, which is very useful tool for the analysis of unknown mechanism of a mixture. To achieve this goal, it is highly desired to have a single, simple and inexpensive analytical method. In this study, we established a HPLC-UV method for simultaneously detecting cefixime in human plasma. The outcomes showed that our HPLC-UV method fully satisfied these conditions as mentioned above. For this method, the plasma preparation for analysis consist of a protein precipitation method. Protein precipitation was necessary and important because this technique can not only purify but also concentrate the sample. Methanol, percholeric acid and acetonitrile were all attempted and acetonitrile: percholeric acid; methanol (75:5:20 $\mathrm{v} / \mathrm{v} / \mathrm{v})$ was finally adopted because of its high extraction efficiency and less interference. Precipitation with and without adding $0.1 \mathrm{M} \mathrm{NaOH}(100 \mu \mathrm{L})$ were both tried, and obvious differences were not observed, so the precipitation using acetonitrile without adding $0.1 \mathrm{M}$ $\mathrm{NaOH}$ was used at last. The validation tests on the developed method showed acceptable degree of linearity, sensitivity, precision, accuracy and recovery for the method.

\section{References}

1. Troy DB, Beringer $P$. The science and practice of pharmacy 2005; 2: 1644. May 19, ISBN-10:0781746736.

2. Katzung B. Basic and clinical pharmacology, (Chapter 8), Chemotherapeutic Drugs tenth ed 2006; 726, ISBN-10:0071451536.

3. Sayed NHA, Bashir I, Nada SHA, Iman RSA, Noora ASA, Nafisur R. Quantitative analysis of cefixime via complexation with palladium(II) in pharmaceutical formulation by spectrophotometry. J Pharm Anal 2013; $3: 248-56$

\section{Conclusion}

An easy HPLC method was urbanized and validated for cefixime evaluate in plasma. Protein precipitation was necessary and important because this technique can not only purify but also concentrate the sample. The validation tests on the developed method indicated acceptable degree of linearity, sensitivity, precision, accuracy and recovery for the method. The method was used successfully for quantization of cefixime in human plasma. System appropriateness tests showed that the residential method is of suitable separation competence and peak shape.

\section{Conflict of Interest}

The authors declared no conflict of interest.
4. Sanofi A. June electronic Medicines Compendium. Available: 2006; http://emc.medicines.org.uk/emc/asset $\mathrm{s} / \mathrm{c} / \mathrm{html} /$ displaydoc.asp?DocumentID $=14540$

5. Duverne C, Bouten A, Deslandes A, Westphal JF, Trouvin JH, Farinotti R, et al. Modification of cefixime bioavailability by nifedipine in humans: involvement of the dipeptide carrier system. Antimicrob Agents Chemother 1992;36:2462-7.

6. Falkowski A, Look ZM. Determination of cefixime in biological samples by Reversedphase high-performance liquid 
chromatography. J Chromatogr Biomed Appl 1987;422:145-52.

7. Meng F, Chen XY, Zeng YL. Zong DF. Sensitive liquid chromatography-tandem mass spectrometry method for the determination of cefixime in human plasma: Application to a pharmacokinetic study .J Chromatogr B 2005;819:277-82.

8. Zendelovska D, Stafilov T, Melosevski P. High-performance liquid chromatographic method for determination of cefixime and cefotaxime in human plasma. Bull Chem Tech Macedoni 2003;22:39-45.

9. Eric-Jovanovic S, Agbaba D, Zivanov-stakik D, Vladimirov S. HPTLC determination of ceftriaxone, cefixime and cefotaxime indosage forms. J Pharm Biomed Anal 1998;18:893-8.

10. Shah PB, Pundarikakshudu K. Simultaneous determination of potassium clavulanate and cefixime in synthetic mixtures by highperformance liquid chromatography.Journal of AOAC International 2006; 89: 987-94.

11. Da-xing X, Ai-min, Fang F. Determination of cefixime in human plasma by HPLC. Guang Chem Ind 2013;208:159-61.

12. Fang M, Xiaoyan C, Yelin Z, Dafang Z. Sensitive liquid chromatography tandom mass spectrometry for the determination of cefixime in human plasma: application to pharmacokinetic study. J Chromatogr B 2005;819:277-82.

13. Raj KA, Divya Y, Deepthi Y, Prabu C, Manikantan S. Determination of cefixime trihydrate, and cefuroxime axetil in bulk drug and pharmaceutical dosage forms by HPLC. Int J Chem Technol Res 2010;2:3346.

14. Azmi SNH, Iqbal B, Al Khanbashi RS, Al Hamhami NH, Rahman, N. Utility of cefixime as a complexing reagent for the determination of $\mathrm{Ni}$ (II) in synthetic mixture and water samples. Environ Monit Assess 2013;185:4647-57.
15. Ethiraj T, ramadoss R, Amudha M. Sensitive spectroscopic method for content analysis of cefixime in solid dosage form using hydrotropy phenomenon. Chron Young Sci 2012;3:299-303.

16. Rajeev J, Vinod KG, Jadon N, Radhapyari $\mathrm{K}$. Voltametric determination of cefixime in pharmaceuticals and biological fluids. Anal Biochem 2010;407:79-88.

17. Ahemed OA. Simultaneous determination of ofloxacin and cefixime in tablet formulation using capillary electrophoresis. J. Liq. Chromatogr. Relat Technol 2013;36:268797.

18. Danafar H, Hamidi M. A Rapid and Sensitive LC-MS Method for determination of ezetimibe concentration in human plasma: application to a bioequivalence study. Chromatographia 2013;76:1667-75.

19. Danafar H, Hamidi M. Pharmacokinetics and bioequivalence study of amlodipine and atorvastatin in healthy male volunteers by LC-MS. Pharm Sci 2015;21:167-74.

20. Danafar H, Hamidi M. Simple and Sensitive High-Performance Liquid Chromatography (HPLC) method with UV detection for mycophenolic acid assay in human plasma. Application to a Bioequivalence Study. Adv Pharm Bull 2015;5:563-8.

21. Danafar H, Hamidi M. Liquid chromatography-tandem mass spectrometry (LC-MS) method for the assignment of enalapril and enalaprilat in human plasma. Pharm Biomed Res 2015;1:47-58.

22. Danafar H, Hamidi M. Simple and sensitive high performance liquid chromatographic method for the simultaneous quantitation of the phenylalanine in human plasma. Pharm Biomed Res 2015;1:12-20. 